\title{
LA DEFENSA Y LOS PROYECTOS DE FORTIFICACIÓN DE VINARÒS EN LOS SIGLOS XVI Y XVII*
}

\author{
Javier Hernández Ruano \\ Universitat de València
}

\begin{abstract}
Resumen: Este artículo analiza el sistema defensivo de Vinaròs durante el siglo XVI y los proyectos de ingeniería para la construcción de una fortaleza moderna en esa villa durante la Guerra de Cataluña (1640-52). Pese a que fueron cuatro los ingenieros que propusieron sus respectivos planes, solo dos de ellos pueden analizarse en profundidad gracias a que se conservan los planos e informes de sus autores, don Francisco de Lorenzana y Castro (1648) y Francisco de Isasi (1649).
\end{abstract}

Palabras clave: Guerra de Cataluña, fortalezas, ingenieros militares, Vinaròs.

The defence and fortification projects of Vinaros in 16th and 17th centuries

Abstract: This article analyzes the defensive system of Vinaros during the sixteenth century and the military engineering projects for the construction of a modern fortress in the same village during the War of Catalonia (1640-52). Although there were four engineers who proposed their respective plans and reports, only two of them can be analyzed in depth thanks to the preserved plans of their authors, Francisco de Lorenzana y Castro (1648) and Francisco de Isasi (1649).

Key words: War of Catalonia, fortresses, military engineers, Vinaros.

\section{INTRODUCCIÓN}

Cuando Felipe IV accedió al trono de la monarquía hispánica en 1621 hacía ya cuatro decenios -desde las treguas hispano-turcas de 1581 y 1584-que la amenaza de un gran desembarco otomano había dejado de sojuzgar los miedos atávicos de los valencianos y formaba parte del recuerdo de una generación que estaba desapareciendo. Aquellos acuerdos entre las dos potencias mediterráneas marcaron "el final de una era", pues la pugna en el mar entre el rey católico y el sultán había terminado (Thompson, 1981, p. 20). Pero es igualmente

Data de recepció: 29 de maig de 2018 / Data d'acceptació: 18 de juliol de 2018.

* Este trabajo se inserta en el marco de un proyecto de investigación del Departament d'Història Moderna i Contemporània de la Universitat de València, titulado "Nuevas perspectivas de historia social en los territorios hispánicos del Mediterráneo Occidental durante la Edad Moderna", financiado por el Ministerio de Economía y Competitividad, con la referencia HAR2014-53298-C2-1-P. 
cierto que el Mediterráneo tardará más de dos siglos aún en desligar su historia de las acometidas de piratas y corsarios (Domínguez, 1996, p. 109). Durante ese dilatado período la intención de navegar en sus aguas todavía constituyó un riesgo que debía sopesarse. Los ataques piráticos a las costas valencianas organizados en Berbería durante la primera mitad del siglo XVII eran tan previsibles como audaces, como demuestra el saqueo de Calp por galeras argelinas en agosto de $1637^{1}$. De hecho, el principal propósito de las escasas fuerzas militares españolas acantonadas en las fortalezas mediterráneas durante la época moderna consistía en alertar y oponerse a este tipo de desembarcos relámpago. En el mar, las propias fronteras delineadas por los corsarios y sus bases portuarias desde el decenio de 1580 complican la interpretación de un Mediterráneo en el que la Monarquía Hispánica y la Gran Puerta impongan su ley (Bunes, 1998, pp. 99).

Toda la concepción estratégica para la defensa del reino de Valencia desde los albores de la edad moderna descansaba en la idea de preservar el control de las playas mediante una vigilancia constante. Hacia ese fin se orientó en el siglo XVI la construcción de atalayas, torres en los muros y más tarde fortalezas modernas, así como el procedimiento para la movilización de las milicias. Durante el reinado de Carlos V, algunas de las murallas de las poblaciones costeras valencianas ya habían sido objeto de proyectos que las adaptaban a la revolución militar, aunque fuese incorporando grandes cubos redondos y baluartes frontales en lugar del bastión clásico de traza italiana en forma de espuntón (Castro y Cobos, 2000, p. 17). En algunos municipios del interior que se vieron amenazados durante la revuelta morisca de 1525, como los que se encontraban en la sierra de Espadán, se llevaron a cabo obras en las murallas que una vez adaptadas para resistir limitados asaltos ya no necesitaron incorporar los gravosos bastiones angulados. Se trata, por tanto, de una "elección consciente" tras evaluar la disponibilidad de recursos y necesidades específicas (Arciniega, 1999, p. 62). El resto de poblaciones del interior, pese a los ambiciosos planes elaborados por Juan Bautista Antonelli en 1561 y 1563, quedaron al margen de aquellas iniciativas, enterradas por su elevado coste en las Cortes de 1564 (Arciniega, 1999, p. 87). El mantenimiento de los recintos murarios medievales a causa del contexto geográfico y social fue particularmente evidente en los municipios que se encontraban en la misma raya con Cataluña, pues nada comprometía la seguridad del nudo de comunicación entre el Principado, Valencia y Aragón si consideramos en su justa medida la posibilidad

1 Archivo de la Corona de Aragón (ACA), Consejo de Aragón (CA), leg. 557, doc. 12/6-7. 
real de que los moriscos (sin aljamas en el norte valenciano salvo Xivert) pudieran apoderarse de alguna población del contorno o que los piratas se internasen en el territorio. En la costa septentrional del reino tan solo se habían erigido muros modernos en el tómbolo de Peníscola, que databan del año 1578, aunque nunca llegaron a solventarse sus imperfecciones (Hernández, 2014, p. 95). En cierto sentido, la escasez de obras defensivas modernas en 1640 se debía también a que en el Consejo de Guerra de la época de Felipe II primó la idea de que la mejor forma de persuadir a los potenciales enemigos de la monarquía en el Mediterráneo era manteniendo una gran flota de galeras (Thompson, 1981, p. 24). Pero fueron sobre todo las treguas hispano-turcas las que determinaron el abandono de los grandes proyectos para levantar en la costa muros adaptados a la guerra moderna.

Este planteamiento de la defensa y la propia dinámica de la situación internacional condujo a que el reino de Valencia no estuviera preparado para afrontar el súbito cambio estratégico que supuso enfrentarse a la guerra moderna también en un frente terrestre. Y a un nivel estratégico general, la Monarquía debía abandonar progresivamente su tradicional planificación ofensiva a gran escala (Hernando, 2013, p. 64). En cuanto a los recursos humanos valencianos se trató de responder mediante ineficaces pragmáticas para la reforma de la milicia efectiva (Requena, 1997, pp. 72-75). Y solo en el último momento, tras la pérdida de Tortosa, se iniciaron planes de fortificación en la frontera. En 1640, aparte de las fortalezas de Peníscola, Dénia y Alacant -todas costerastan solo el castillo de Santa Pola y el baluarte angular de la casa de las armas de València, construido entre 1574 y 1581 y símbolo del reino (Arciniega, 2016, p. 128) contaban con baluartes a la moderna. Puede afirmarse que la historia militar valenciana en la década de 1640 es también el relato de un intento por adaptarse al cambio fundamental que suponía afrontar la defensa a partir de los movimientos de grandes ejércitos tierra adentro. En un principio esto se tradujo en una movilización de la población local sin precedentes desde las Germanías, pero mucho más prolongada en el tiempo, cuyas consecuencias también socioeconómicas requieren un estudio en profundidad, y que en el caso del Maestrazgo de la Orden de Montesa tuvo un profundo impacto (Hernández, 2014b, pp.334347). En las siguientes líneas nos centramos en la vertiente poliorcética de esa adaptación y sus efectos en el caso específico de Vinaròs, donde se promovieron en 1648 y 1649 tres proyectos (con la intervención de cuatro ingenieros militares) para levantar una fortaleza moderna en el contexto de la guerra de Cataluña (1640-1653). Pero antes nos detendremos en el estado de las murallas de Vinaròs desde la época de Felipe II hasta 1640. 


\section{LAS DEFENSAS DE VINARÒS EN EL SIGLO XVI}

A la muralla de Vinaròs y a la organización de su propia defensa dedicó una extensa digresión Martín de Viciana en su conocida Crónica. La lectura de este pormenorizado fragmento permite una aproximación al estado de la estructura muraria y su funcionamiento justo después de que en 1560 se hubieran reforzado las murallas y ampliado el recinto fortificado (Oliver, 2007, p. 12), lo que nos ofrece además un punto de partida para interpretar la magnitud de los proyectos de 1648 y 1649. Según el relato del cronista de Borriana, la población contaba con ocho "torres" y "baluartes" dispuestos a lo largo de un "quadro" con foso (Viciana, 1564, p. 126). Recientes excavaciones arqueológicas han permitido constatar la existencia de seis torres cuadradas situadas en el extremo de las calles dada su función como portales. Así mismo se ha confirmado la existencia del foso y sus dimensiones ( 3 metros de profundidad y entre 5,5 y 6 metros de anchura) lo que obligaría a mantener diferentes puentes levadizos (Oliver, 2007, p. 17). Es posible que Viciana distinguiese entre torres y baluartes con la intención de destacar los tres grandes torreones redondos -en el ángulo noroeste se ubicaba la iglesia- que guardaban las esquinas del cuadrilátero. Aunque no se haya encontrado evidencia arqueológica, pueden identificarse en el delineamiento del recinto antiguo que contenían los planos de los ingenieros Francisco de Lorenzana (1648) y Francisco de Isasi (1649). Los tres torreones aparentemente seguían el patrón constructivo de las torres troncocónicas erigidas en otros lugares del reino como adaptación autóctona a la revolución militar desde el decenio de 1530 (Pardo, 2000, pp. 148-149). La disposición, proporción relativa y preeminencia de dichas estructuras respecto al conjunto amurallado puede distinguirse con precisión en el detalle del recinto antiguo que hemos extraído del plano de Lorenzana (figura 1), que también representa todo el cuadrilátero al que se refirió Viciana. Al mismo tiempo destaca la iglesia-fortaleza construida en 1594 en la esquina norte y la esbelta torre adyacente que se añadió pocos años más tarde (Borràs, 1929, p. 141).

En un informe de 1649 el ingeniero Francisco de Isasi consignó la anchura del muro, que según sus cálculos alcanzaba la apreciable cifra de cinco pies "y en muchas partes más de seis", aunque al mismo tiempo reconocía que era inservible para resistir un asedio porque era recto (Baila, 2003, p. 27). Esta falta de alambor y suficiente anchura las exponía mucho más a la destrucción en caso de que recibieran el impacto continuado de balas de artillería. Y esto era ciertamente un serio riesgo en el contexto de la década de 1640. El desdén que evitó Isasi al enjuiciar la muralla lo manifestó sin ambages el virrey Oropesa en 1648 al describirla: "tiene quatro torreoncillos a las esquinas que son 
Fig. 1. Detalle del plano de Francisco de Lorenzana y Castro con la estructura muraria de Vinaròs, 1648. España. Ministerio de Educación Cultura y Deporte, Archivo General de Simancas, MPD, 9, $59.57 \times 84 \mathrm{~cm}$.

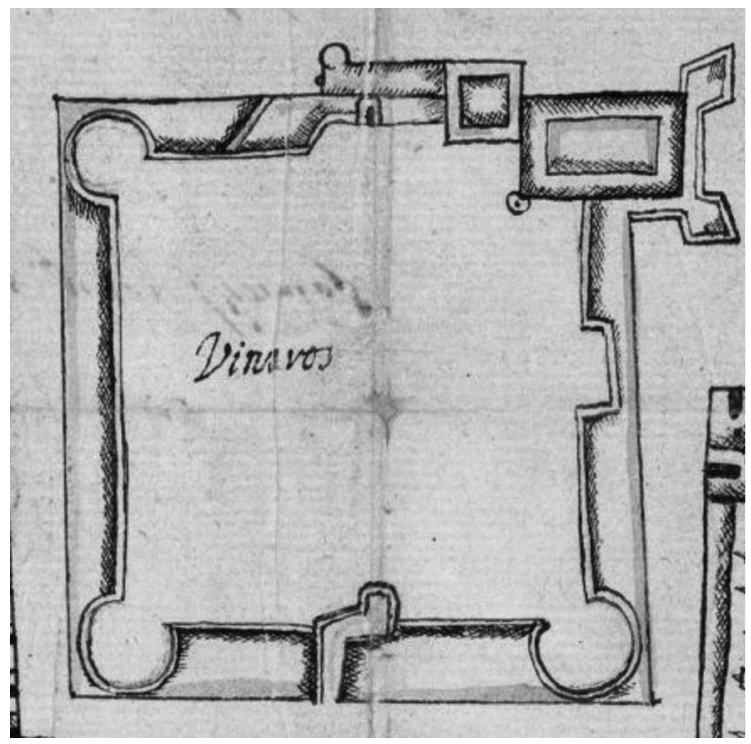

de poca subsistencia...”. Al despreciar todo aquello que no se ajustase a las características de las esbeltas fortificaciones modernas estimó que la única solución era derribar toda la muralla vieja: "la muralla de la villa es un casamuro antiguo sin género de través (...) el dia que se aya de tratar de fortificar regularmente este puesto es neceçario no hacer caso de la muralla antigua y empeçar el recinto desde los çimientos..."2.

Además del sistema murario, la valoración de la capacidad defensiva de la población requiere que consideremos otros aspectos no menos importantes como el armamento y la planificación de la defensa. Vinaròs disponía a comienzos del reinado de Felipe II de un significativo número de piezas de artillería y armas de fuego, que Viciana cifró en doce cañones entre piezas de bronce, medias culebrinas, sacres y otros cañones, así como cincuenta arcabuces. Este armamento debe relacionarse con la ponderación que hiciera Viciana de la marcialidad de los vecinos, que convertía Vinaròs en el lugar del reino "más concertado, bien armado, proveydo y apercibido de toda la costa" (Vi-

2 Archivo General de Simancas (AGS), Guerra Antigua (GA), leg. 605, doc. 25/22, el virrey al rey, 4/8/1648. Citado en: Gil Saura, Y. (2004): Arquitectura barroca en Castellón, Castellón de la Plana, Diputación de Castellón, p. 27. 
ciana, 1564, p. 126). En caso de ataque, cinco capitanes con sus respectivas banderas y cuatro alféreces, provistos también de una bandera y tambor, se encaramaban a los muros y cubrían los cuatro lienzos con un número de vecinos asignado previamente. El justicia era el encargado de dirigir las operaciones desde lo alto de la iglesia parroquial, asistido por un alférez con su bandera, seguido por setenta jóvenes aprestados para acudir a cualquier segmento del recinto cuya resistencia se viera comprometida. En teoría se contaba también con el socorro que pudiera organizarse a tiempo procedente de todo el Maestrazgo viejo de la Orden de Montesa, como ocurrió tras el intento de desembarco de Salah Rais con trece galeras en 1545 (Viciana, 1564, p. 126). También se vio frustrada una incursión de este corsario dos años después en Alcalà, a unas pocas leguas más al sur, población que contaba con un sistema defensivo similar al de Vinaròs, pues también giraba en torno a una iglesia-fortaleza. En 1585, la descripción por parte del párroco de las obras que había incorporado el templo de esa villa nos remite al paradigma de un sistema defensivo que dependía de una iglesia-fortaleza, pues su tejado estaba "rodeado de muros y troneras, y una garita que guarda la puerta principal. Y en dicho terrado están puestas dos piessas de artillería y se acostumbra de ordinario poner guardas o sentinelas..." (Iturat, 1989, p. 69).

Podemos hacernos una idea más precisa de las dimensiones que alcanzaban las torres redondas de Vinaròs en relación al resto de la estructura muraria si interpretamos en la pintura de Pere Oromig y Francisco Peralta sobre el embarque de los moriscos en sus playas (figura 2). Se representan en el óleo piezas de artillería encabalgadas sobre la torre del portal del mar y en las dos torres redondas que la flanqueaban, lo que es compatible con las características sustentantes de las torres troncocónicas valencianas de la etapa de Carlos I. En un dibujo de la villa realizado en 1654 para un libro de Aniversarios (Oliver, 2000, p. 43) de la arciprestal (figura 3) también se destacaron las piezas de artillería apuntando al mar. Y tanto en una como en otra representación destaca el gran número de aberturas para el uso de armas de fuego en la muralla, la iglesia-fortaleza y su torre.

El Consejo de Aragón se refirió a la naturaleza y función del recio templo, erigido en 1594 "a modo de fortaleza, por necesitar della ansí para el servicio y culto divino como para en tiempo de enemigos de nuestra fe cathólica..." (VV.AA, 2014, p. 121). De hecho, la nave y su portentosa torre se concibieron como un fuerte integrado en el recinto amurallado. Hay que destacar que los diferentes huecos abiertos en el muro de esta iglesia no respondían a la función de unos simples vanos sino a la de una serie de troneras en la cubierta y otras aberturas realizadas a diferentes alturas para la utilización de arcabuces y mosquetes. Los alzados oeste y norte del templo muestran el poder defensivo de la 


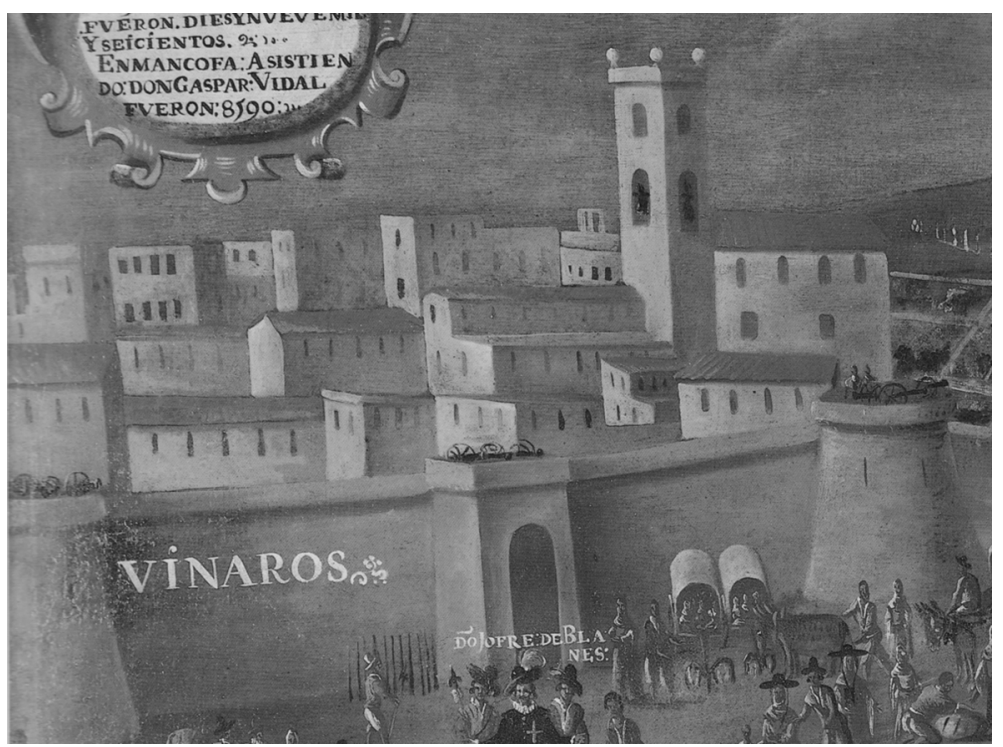

Fig. 2. Detalle de la pintura Embarque de los moriscos en el puerto de Vinaròs, Pere Oromig y Francisco Peralta, 1612-13.

Fig. 3. Representación de Vinaròs en el libro de Aniversaris de la arciprestal, 1654.

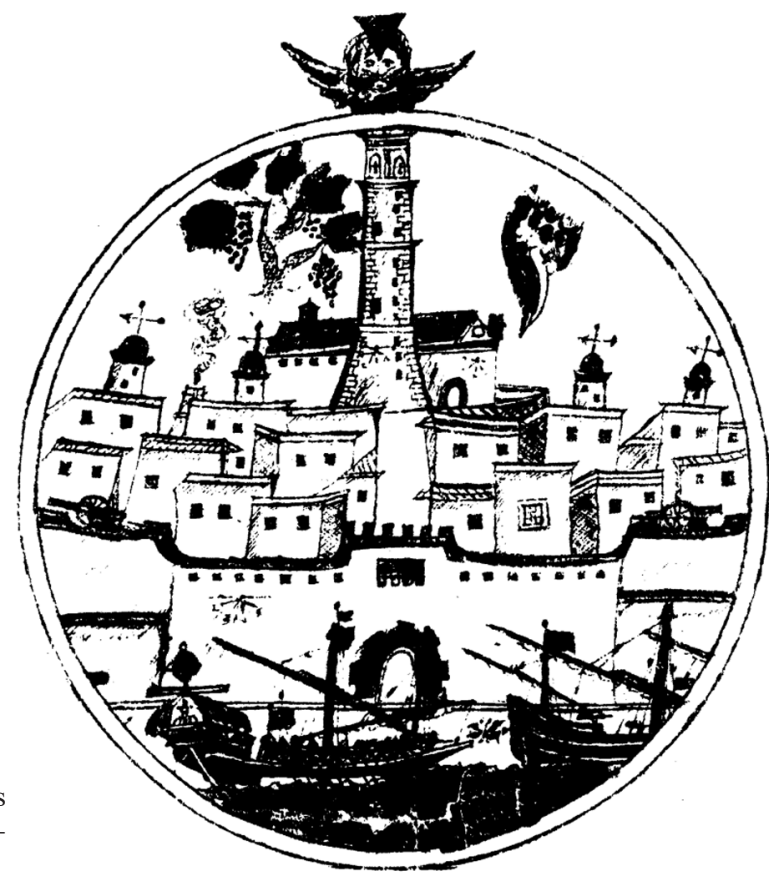




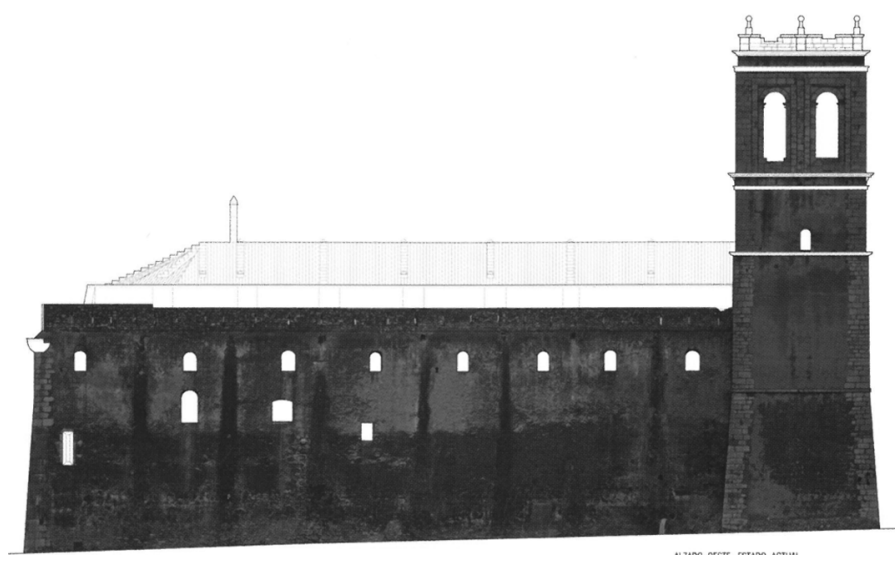

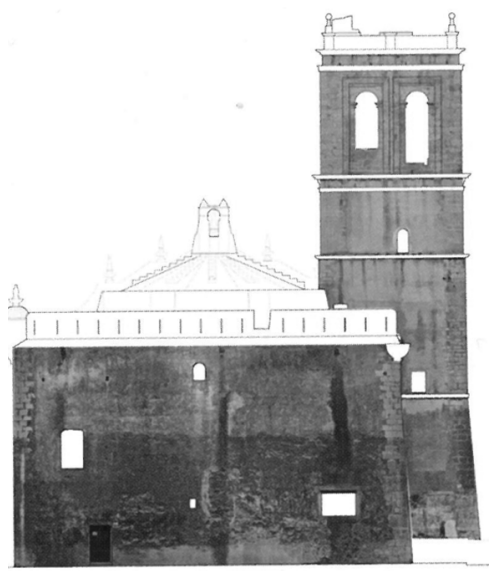

Fig. 4a y 4b. Alzados oeste y norte de la iglesia-fortaleza de Vinaròs (1594) con sus aberturas para piezas de artillería y armas de fuego (VV.AA, 2014, p. 125).

nueva fábrica, que solo en el lado oeste (figura 4a) contaba con ocho bocas de cañón. Cuatro garitas en las esquinas se comunicaban por un deambulatorio para facilitar la circulación de centinelas y artilleros. La cubierta y el deambulatorio conectaban con el resto de la muralla y la torre a través de una estancia (VV.AA, 2014, pp. 124-125). Los dos lados del templo más alejados del recinto quedaban protegidos por el fuego de flanco que ofrecía la torre (figura $4 b$ ).

El sistema defensivo deslindado en las líneas anteriores era el que sostenía la seguridad de los vecinos de Vinaròs cuando estalló la rebelión de Cataluña en 1640. Pero a partir del verano de ese año este paradigma quedó obsoleto y hubo de adaptarse a la circunstancia de que la amenaza no procedía únicamente del 
mar ni se reducía al conocido modo de operar de los corsarios. Por primera vez en su historia moderna, el reino de Valencia se enfrentaba a una inminente invasión terrestre de un gran ejército, provisto de los últimos avances en armas de fuego. La Guerra de los Treinta Años se había presentado con toda su crudeza ante sus puertas. En caso de que se perdiese Tortosa, considerada por los valencianos como su antemural, la guerra en territorio valenciano era cuestión de tiempo, como estuvo a punto de ocurrir en la primavera de 1642 y finalmente se consumó en julio de 1648. Una vez perdida la plaza, ¿qué soluciones adoptó la corte para enfrentarse a la defensa del reino de Valencia ante el riesgo inminente de invasión? ¿En qué medida afectaron esas decisiones a la villa de Vinaròs?

\section{REFORMAS EN LAS MURALLAS Y PROYECTOS DE INGENIERÍA (1640-1649)}

Desde mayo de 1640 las noticias de los disturbios en Cataluña con motivo de los desmanes de las tropas reales allí alojadas eran cada vez más preocupantes (Elliott, 1990, p. 632). Ya el 5 de abril, las autoridades de Vinaròs habían sido conminadas a redoblar la vigilancia y prepararse para cualquier eventualidad. En junio, las medidas preventivas se ampliaron con rondas nocturnas y pocas semanas después el recinto amurallado fue objeto de una meticulosa inspección que estimó conveniente aumentar la altura de las torres (Borràs, 1924, pp. 253-255). Una vez consolidada la rebelión catalana, y tras el estallido de un motín en Tortosa el 21 de julio -que no se sofocó hasta el 4 de septiembrepor primera vez se vislumbró la posibilidad de que la frontera valenciana se convirtiera en la línea del frente. Fue dicha eventualidad la que apremió a las autoridades locales a realizar las reformas planteadas a comienzos del verano. Las torres se alzaron más de 2 metros, el foso se inundó de agua, los portales se reforzaron con estacadas, se encabalgó un obús en cada torre y se incorporaron al arsenal local 100 arcabuces y 100 mosquetes (Oliver, 2007, p. 28).

\section{La idea de un puerto y la creación de una junta de guerra (1640-42)}

Mientras se debatía en la corte la intervención militar en el Principado (Elliott, 1990, p. 642), el rey ordenó el 4 de agosto que se determinara si la rada de Vinaròs era apta para la construcción de un puerto donde pudiesen fondear con seguridad las galeras. En los días inmediatamente siguientes unos "ingenieros de muelles" inspeccionaron el lugar y dieron el visto bueno al proyecto. Antes de que acabase ese mes el ingeniero italiano Jerónimo Marqueli había 
sido escogido para iniciar los trabajos ${ }^{3}$. La decisión fue seguramente recibida en la población como un gran logro, ya que el Consell se había mostrado especialmente favorable en un memorial a que prosperase el plan ${ }^{4}$. La iniciativa fue probablemente fomentada por los comerciantes locales, que esperaban aprovechar la infraestructura para promover sus negocios. Finalmente, la operación se desestimó debido a que prevalecieron las consideraciones estrictamente militares. El 7 de noviembre, los marqueses de los Balbases y Castrofuerte se decantaron porque fuese Peníscola la población que albergase un puerto, aludiendo a que las naves gozarían de la protección de sus murallas modernas, además de que la pequeña península contaba con manantiales de agua dulce para el abastecimiento de las galeras, tal y como recordó el gobernador de la fortaleza (Hernández, 2014, pp. 63-64).

Aunque Vinaròs perdiese tan importante infraestructura, su papel durante los años siguientes será trascendental en la organización de la guerra. Dada su localización geográfica, en la costa y en la misma raya, fue escogida como plaza de armas y centro de abastecimiento de Tortosa y Tarragona junto al puerto de Els Alfacs (Camarero, 2015, p. 68). Ocho mil soldados al mando del marqués de Leganés se concentraban en Vinaròs en mayo de 1642 (Elliott, 1990, p. 693) y desde entonces nunca dejaron de acantonarse cientos de tropas en la villa que, pese a ser posteriormente redistribuidas, debían ser antes alojadas y atendidas, como lamentó reiteradamente el gobierno local. Esta circunstancia ha de considerarse como la primera consecuencia de las iniciativas tomadas por la corte respecto a la frontera valenciana y singularmente en el caso de Vinaròs. También se creó una Junta de guerra cuyo propósito consistirá en la supervisión de la logística para abastecer las fortalezas costeras catalanas y el ejército real alojado en ellas 5 . El 2 de octubre de 1642, el rey aprobó una consulta de la Junta de Ejecución que proponía la creación de una Junta de guerra en Vinaròs. Esta decisión seguía una costumbre implantada por Felipe II, que consistía en la formación de instituciones ad hoc como prolongación de los grandes Consejos de la monarquía, con la intención de liberarlos de asuntos específicos, y por las que el conde-duque sintió una especial predilección. La re-

3 ACA, CA, leg. 286, doc. 53, la Junta de Ejecución al rey, 28/8/1640. Citado en: Cámara Muñoz, A. (coord.), (2005): "Esos desconocidos ingenieros", en: Los ingenieros militares de la monarquía hispánica en los siglos XVI y XVII, Madrid, Ministerio de Defensa y Asociación Española de Amigos de los Castillos, p. 23.

4 ACA, CA, leg. 233, doc. 97-1/20.

5 Sobre la junta de Vinaròs he presentado un trabajo al Congreso Internacional: "Recordar la guerra, construir la paz", 450 aniversario de la guerra de las Alpujarras, Granada, noviembre, 2018. 
lación de miembros de la Junta continuaba con la tradición de que sus integrantes fueran hombres que ya pertenecían a otros Consejos, expertos en armas o en leyes: don Diego Fajardo, el barón de Auchi, don Pedro de Villacampa y el veedor general don Diego Bernardo de Eraso y Cárcamo ${ }^{6}$. Los dos primeros formaban parte del Consejo de Guerra; Eraso era un oficial real con experiencia como veedor en Sicilia ${ }^{7}$ y Villacampa era uno de los oidores de la Real Audiencia valenciana, pero al parecer no formó finalmente parte de la Junta por consejo del virrey, quien estimó que su trabajo sería más útil en la capital del reino. Completaba la lista una serie de oficiales a los que se asignó un sueldo ${ }^{8}$. Se trataba de un mayordomo, al mando de la teneduría de municiones y artillería, más un indeterminado número de tenedores de bastimentos 9 .

La misión de la Junta estaba consagrada al socorro de las plazas de Roses, Tarragona y Tortosa, al alojamiento y tránsito de tropas hacia Cataluña e Italia, el aprovisionamiento, transporte y almacenamiento de bastimentos, el control de un arsenal, así como la distribución de grandes cantidades de dinero para gastos destinados al ejército y la reparación de fortalezas ${ }^{10}$. De las dificultades logísticas a las que se enfrentaba la Junta valga como ejemplo un testimonio de don Rodrigo de Borja, gobernador de la villa, al informar al rey en octubre de 1643 de la llegada de once galeras de la escuadra de Nápoles al mando del duque de Medinaceli con un regimiento de 1.289 alemanes destinados a engrosar las filas del ejército real alojado en Aragón:

[...] Yo me hallo sin orden de Vuestra Magestad, ni del duque de Arcos, para saber lo que he de hacer desta gente, ni ninguna forma ni con que podellos socorrer. Y no es gente que se pueda echar en tierra sin socorro, así por su condición como por las mujeres y niños que traen, ni es posible aquartelalla en estos contornos por averse de acuartelar en ellos la ynfantería de Siçilia $[\ldots]^{11}$

${ }^{6}$ ACA, CA, leg.565, doc. 23. El Consejo de Aragón al rey, 3/10/1642.

7 AGS, Estado, leg. 3594, doc. 210/14,16,20,21,13.

8 AGS, GM, leg. 1462, 3/10/1642 y leg. 1498, 26/II/1643.

9 AGS, GM, leg. 1554, don Rodrigo de Borja al rey 14/9/1644 y leg. 1600, don Rodrigo de Borja al rey, 15/6/1645.

10 AGS, GM, leg. 1497, la junta de Vinaròs al rey, 12/2/1643, Relación de gastos: 18/2/1643.

11 AGS, GM, leg. 1497, la junta de Vinaròs al rey, 7/10/1643. El destino de los alemanes era el ejército de Aragón como se deduce de la conducción a Alcañiz de otro contingente de alemanes que había llegado en agosto: AGS, GM, leg. 1497, el virrey duque de Arcos al rey, 21/8/1643. 


\section{El plan incipiente para la construcción de una fortaleza real en la frontera $(1642-43)$}

El motín de Tortosa del verano de 1640, y de manera más evidente el doble ataque francés a esa misma ciudad en abril de 1642, supusieron una contundente advertencia sobre la eventual exposición del reino de Valencia a una invasión. El dominio del campo de Tortosa por las tropas del general La Mothe-Houdancourt puso en evidencia la extrema vulnerabilidad de la frontera valenciana y, lo que era peor, que nada podía impedir que en pocas jornadas de marcha el ejército franco-catalán pudiera presentarse ante las puertas de la capital. Esa situación no solo era resultado de la debilidad del ejército real sino de la inexistencia de fortalezas modernas en la raya, lógica por otra parte, ya que la concepción defensiva desarrollada durante décadas no contemplaba ese extremo. El desamparo de la raya de Aragón era similar de manera que todo el esfuerzo en las fronteras iba a depender en lo sucesivo de la movilidad del ejército real (Camarero, 2015, p. 141). Esta era la desoladora realidad a la que se enfrentaron los virreyes valencianos durante el decenio de 1640, desde don Fernando Colonna hasta el conde de Oropesa. El duque de Gandía, por ejemplo, insistió al rey el 22 de abril de 1642 -en pleno dominio francés del campo de Tortosa- que era imposible detener a los franceses si avanzaban sobre la frontera, y unos días antes ya había augurado que la guerra penetraría en suelo valenciano si caía la ciudad ${ }^{12}$.

Los hechos de la primavera de 1642 espolearon seguramente la idea de levantar fortalezas, pues la primera mención documental está datada solo unos meses después de que se produjeran aquellos críticos acontecimientos. El hecho de que los franceses persistieran en su ofensiva tras el fracaso en Tortosa y lanzasen una gran operación anfibia sobre Vinaròs el 26 de junio al mando de Henri d’Escoubleau de Sourdis, arzobispo de Burdeos, finalmente frustrada por las milicias locales ${ }^{13}$, convenció a las autoridades de Vinaròs de que si no tomaban la iniciativa quizás la solución de la corte llegase demasiado tarde. De hecho, en septiembre, el marqués de Leganés al mando de la logística en la frontera y el virrey aprobaron la petición de la villa de que se le remitiesen seis cañones de hierro y pudieran recuperar otras tres piezas holandesas del fondo del mar, así como construir un baluarte delante del mar porque "los ba-

12 ACA, CA, leg. 565, doc. 7/2-7, el duque de Gandía al rey, 17/4/1642 y el doctor Bono al virrey, 22/4/1642.

13 ACA, CA, leg, 883, doc. 70, el Consejo de Aragón al rey, noviembre, 1642. 
luartes de la villa donde está la artillería padescen en esta parte"14. En noviembre se remitieron las ocho piezas y la Diputació sería la encargada de financiar la construcción del baluarte (Camarero, 2015, p.336). La amenaza de invasión persistía y es plausible que durante el verano de 1642 se tratara en el Consejo de Guerra la idea de construir fortalezas en la frontera. De hecho, en febrero de 1643 ya se había tomado la decisión de que el ingeniero don Baltasar Fort, capitán de infantería del Batallón de València, inspeccionase la raya con la intención de que se levantase una fortaleza, "cuanto más arrimada a la raia para que cubra todo el reyno y este pedaço de muy bien firme de San Matheo y Traiguera..."15.

Pese a que por primera vez la corte contemplaba un plan de esta naturaleza, si interpretamos los hechos posteriores se colige que los consejeros de guerra estimaron que su ejecución se condicionaría a la suerte que corriese la plaza de Tortosa, que por el momento se mantenía en poder de los españoles. En octubre de 1645, dos años después de la inspección del ingeniero Fort, durante la celebración de Cortes en València, y pese a que el propio virrey se había presentado en la raya para organizar la defensa del reino durante el mes de julio (Guia, 1984, p. 37), don Rodrigo de Borja (gobernador de Vinaròs) recordó a Felipe IV que esa villa ni siquiera contaba con guarnición. La razón de la misiva había sido un alarmante aviso de don Baltasar de Rojas Pantoja, gobernador de Tortosa, quien aseguró a Borja que 3.000 infantes y 800 caballos al mando del conde de Chabot se disponían a ocupar la castellanía de Amposta o Ulldecona e interrumpir el paso de bastimentos desde Vinaròs. Borja hubo de ordenar que toda la población de la frontera se refugiase en aquellas villas que contaran con murallas ${ }^{16}$. No era ni mucho menos la primera ocasión en que se producía una alarma ante la posible incursión de tropas francesas o migueletes a través de la frontera. De hecho, el Maestrazgo había adquirido una larga experiencia en enfrentarse a esas limitadas acciones, aunque el peor momento vivido hasta la fecha había sido sin duda el frustrado desembarco en Vinaròs de junio de 1642 (Hernández, 2013, pp. 6-45). Sin embargo, la situación cambió por completo a partir del verano de 1648. Y este giro de la rueda de la fortuna accionó la espoleta de los planes de fortificación.

\section{Los proyectos de ingeniería de 1648 y 1649}

Cuando los franceses bajo el mando del mariscal Charles de Schomberg ocuparon el campo de Tortosa e iniciaron el segundo asedio de la ciudad en la

\footnotetext{
14 ACA, CA, leg. 883, ACA, CA, 70/1-8, el Consejo de Aragón al rey, 6/11/1642.

15 ACA, CA, leg. 564, doc. 12/4, el Consejo de Aragón al rey, 28/2/1643.

16 AGS, GM, leg. 1600, don Rodrigo de Borja al rey, 31/10/1645.
} 
primavera de 1648 no se había producido ningún cambio en la situación de indefensión de la frontera valenciana, denunciada por don Rodrigo de Borja tres años atrás. Como se ha adelantado más arriba, las evidencias sugieren que el Consejo de Guerra se mantenía a la expectativa ante lo que podía ocurrir en Tortosa para activar el plan de fortificación atisbado en el verano de 1643. Los planos de 1648 y 1649 delineados por don Francisco de Lorenzana y Francisco de Isasi, así como el informe de este último, demuestran que desde el estallido del conflicto nada relevante se había hecho en la población a excepción posiblemente de una estructura incorporada al templo en su lado norte, que Isasi identificó como una "caponera" que comunicaba el templo con el paso de ronda de la muralla.

La noticia de que los franceses habían rendido la plaza de Tortosa el 14 de julio consternó a las autoridades españolas, pues se abría ahora un nuevo frente que amenazaba València y no existía ya otra fortaleza que pudiera incomodar el avance de los franceses hacia el sur, pues tanto Morella como Peníscola se encontraban muy alejadas del camino real. En Sant Mateu se formó inmediatamente una junta con el propósito de discutir las medidas más urgentes. Estaba integrada por el virrey de València, conde de Oropesa, el comandante general del ejército real en Cataluña, don Francisco de Melo, y las dos primeras autoridades militares de la Orden de Montesa, su lugarteniente general y el lugarteniente. Todos asumieron que el momento era grave ante la escasez de fuerzas reunidas en la frontera y que no existía más alternativa que levantar fortalezas en Vinaròs, Traiguera y Canet lo Roig ${ }^{17}$, pues estas poblaciones cubrían la zona por la que podía transitar un ejército a través de la frontera. El ingeniero escogido por don Francisco de Melo para llevar adelante el perentorio proyecto fue Pedro Alexandre, teniente de maestre de campo general del ejército real. La opción de Canet lo Roig fue descartada muy pronto, pues solo existe constancia de que Alexandre trazó el 21 de julio una planta para Traiguera y otra para Vinaròs, de cuyos planos e informes solo hemos podido localizar los de Traiguera ${ }^{18}$.

Durante el contexto del asedio a Tortosa en la primavera de 1648 los franceses habían promovido una serie de escaramuzas en la frontera. Cuatro de ellas habían tenido como objetivo tomar el puente norte de Vinaròs, que se encontraba fortificado $^{19}$. Tras la toma de la ciudad, ochenta caballeros volvieron a atacar el mismo puente el 20 de agosto, donde pelearon con las milicias del tercio de don Juan de Castellví. Los defensores repelieron el ataque, que resultó

17 ACA, CA, leg. 605, doc. 5/1, el conde de Oropesa al rey, 14/7/1648.

18 AGS, GA, leg. 1679, declaración de Pedro Alexandre, 19/9/1648.

19 AGS, GA, leg. 605, doc. 4/1, el conde de Oropesa al rey, 19/6/1648. 
en la muerte de algunos soldados de ambos bandos. Algunas semanas más tarde, al recibir noticias de que el mariscal Ferdinand de Marchin estaba preparado para marchar con 3.000 hombres sobre Vinaròs, el conde de Oropesa interpretó que el propósito del primer ataque había sido medir los efectivos con los que contaba la villa para defenderse. El virrey explicó a la corte que esa ofensiva finalmente se frustró ante las noticias de que la peste había alcanzado la villa (Hernández, 2013, p. 13).

Las obras en Traiguera, comenzadas a inicios de agosto, se encontraban bajo la supervisión del ingeniero don Francisco de Lorenzana y Castro, quien diseñó también una planta para Vinaròs. Felipe IV lo había aprobado pese a que el virrey Oropesa se mostrase ahora firmemente partidario de concentrar todos los recursos en Traiguera. El virrey desaconsejaba la construcción simultánea de las dos fábricas dado el elevado coste en recursos y tiempo. Además, estaba convencido de que Traiguera reunía las mejores condiciones por cubrir "el carril por donde ha de conducir el enemigo su artillería y de estar en paraje que por falta de agua no se podría mantener, habiéndola de sitiar después de fortificado..." ${ }^{20}$. Con la solución de esta disyuntiva en manos de los consejeros de guerra el ingeniero Lorenzana comenzó a trabajar sobre el proyecto de Vinaròs. Por indicación del virrey delineó primero un esquema general del trazado urbano de los arrabales para estudiar su demolición (figura 5) 21 $^{21}$ advirtiendo que la mayor parte de las casas del interior de la fortaleza debían permanecer en pie. El rey era partidario de que solo en caso de que el grueso del ejército atacase la población debían quemarse las viviendas de los arrabales "para que no se aloje", opinión discutida por el virrey por razones militares y políticas: los muros de las casas no arderían, dejando a los franceses la oportunidad de abrir troneras para batir la villa. Además, la mayor parte de esas viviendas debían aprovecharse para formar el perímetro de la nueva fortificación. Oropesa desaconsejó también derribar los arrabales por el impacto que causaría en la opinión local, ya que "será materia muy sensible para los naturales el ver destruir por nuestras manos sus casas" (Baila, 2008, p. 73).

El proyecto de la fortaleza delineado por don Francisco de Lorenzana dibujaba un colosal pentágono abastionado que circunvalaba la villa e incluía un foso (figura 6). Las condiciones del terreno llano condicionaron la planta, organizada como un polígono de proporciones perfectas típico de las concepciones

${ }^{20}$ ACA, CA, leg. 605, doc. 25/20, el rey al conde de Oropesa, 13/8/1648, leg. 555, doc. 25/17, el Consejo de Aragón al rey, 12/8/1648.

${ }^{21}$ El plano reproducido y comentado en: Baila Pallarés, M.A. (2008): Lloc, Vila i Ciutat: evolució urbana de Vinaròs (segles XIII-XX), Vinaròs, Antinea, p. 72. 


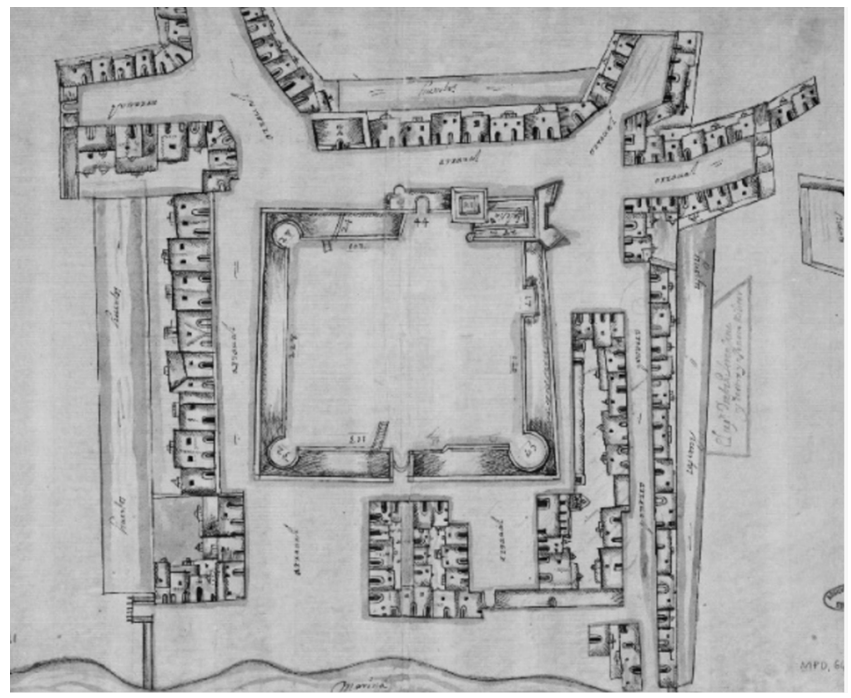

Fig. 5. Los arrabales de Vinaròs en un plano de Francisco de Lorenzana y Castro, 1648. España. Ministerio de Educación, Cultura y Deporte, Archivo General de Simancas, MPD, 64-24, 43 x $31 \mathrm{~cm}$.

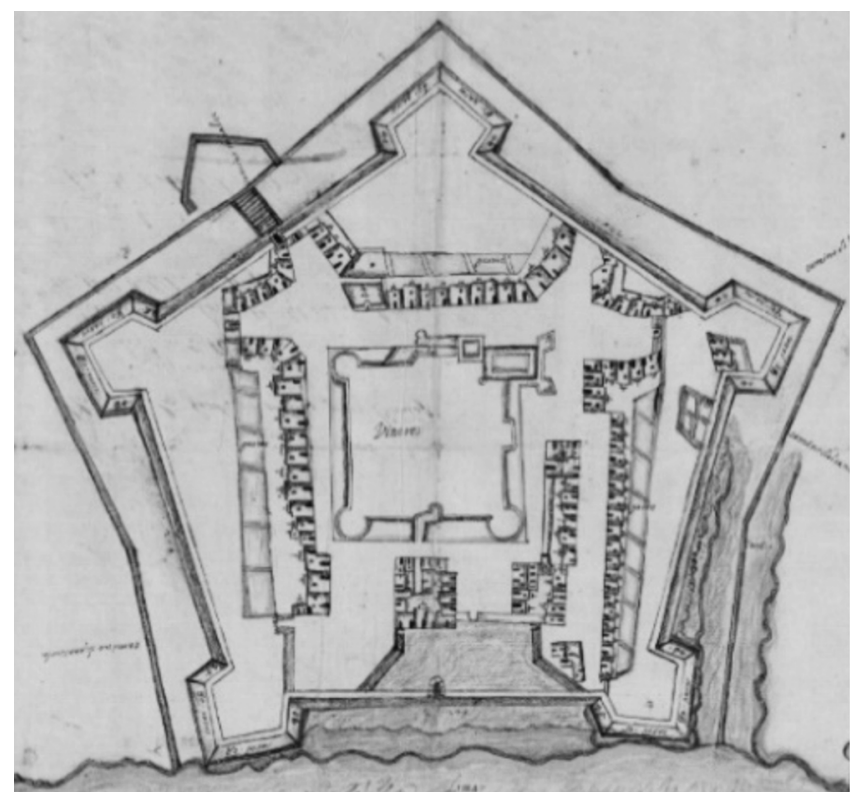

Fig. 6. Plano de una fortaleza pentagonal para Vinaròs de don Francisco de Lorenzana y Castro, 1648. España. Ministerio de Educación y Cultura. AGS, MPD, 64-25. 54 x $42 \mathrm{~cm}$. 
ortodoxas, a diferencia de la construcción heterodoxa que podía ensayarse en el terreno irregular de Traiguera. En todo caso, como ocurría desde el siglo XVI los ingenieros partían siempre de unas premisas para obtener el número de lados y el ángulo de los bastiones. La distancia entre la punta de un bastión y el flanco contiguo la determinaba el alcance de un arcabuz; el número de lados dependía de la relación entre esa magnitud y la cabida del recinto (Cobos y Castro, 2005, p. 83). Para adaptarse a la posición costera de Vinaròs Lorenzana emplazó dos bastiones orientados hacia el mar. Los otros tres protegerían la villa en caso de ataque terrestre. La longitud de los dos frentes de esas estructuras anguladas se había previsto que fuese de 80 pasos ( $42 \mathrm{~m}$.), en los traveses de 40 pasos ( $31 \mathrm{~m}$.) y en las cortinas de 240 pasos (186 m.) (Baila, 2008, p. 73). Como puede apreciarse en el plano, el muro antiguo se integraba en la nueva fortificación al formar un recinto interior que podía utilizarse como refugio y segunda línea de defensa. La iglesia-fortaleza continuaría siendo un punto igualmente fuerte y ventajoso como puesto de vigilancia, que como ya se ha mencionado contaba con un moderno sistema defensivo que permitía la utilización de artillería y armas de fuego desde diferentes ángulos.

Una vez elaborados los informes y delineados los planos sobre las fortalezas de Traiguera y Vinaròs a los pocos días de la pérdida de Tortosa, y con las obras de Traiguera ya iniciadas, el reino movilizó los tercios de las milicias con la pretensión de ofrecer alguna resistencia ante una posible invasión. A lo largo de la raya se alojaban a comienzos de agosto alrededor de 3.000 tropas, de las cuales solo 400 eran veteranos que había dejado allí Melor ${ }^{22}$. En esos días surgió algún tipo de desencuentro entre el virrey y Lorenzana, que desembocó en la salida del ingeniero y la petición del conde de Oropesa de que se desplazasen a la frontera los ingenieros don Ventura de Tarragona y el jesuita Francisco de Isasi (Baila, 2008, p. 21), este último catedrático de matemáticas en el Colegio Imperial de Madrid y miembro de una familia de ingenieros guipuzcoanos (Cobos y Castro, 2005, p. 83). El 30 de septiembre, don Ventura de Tarragona visitó Traiguera junto al alemán Jorge Juan, barón de Seebach, un veterano de caballería del ejército de Melo que dominaba el castellano y que acababa de ser designado maestre de campo general para la defensa de la frontera, cuyo cuartel se encontraba en Sant Mateu. Como había hecho Alexandre, Ventura de Tarragona diseñó nuevas plantas para Traiguera y Vinaròs, de las que

22 ACA, CA, leg. 605, doc. 26/1, el Consejo de Aragón al rey, 30/8/1648; Id. doc. 26/2, el conde de Oropesa al rey, 25/8/1648. ACA, CA, leg. 605, doc. 26/4, el conde de Oropesa al rey (12/8/1648). Relación de todos los soldados de los Tercios de infantería de los batallones de la ciudad y reyno de Valencia..., 5/8/1648, certificado por el virrey el 13/8/1648. 
solo hemos localizado la primera (Hernández, 2014, p. 73). Sin embargo, conocemos el planteamiento general de la traza del proyecto para Vinaròs gracias a una carta del barón de Seebach en la que éste informó al virrey de que Tarragona había diseñado para Vinaròs "una planta la qual es de quatro valuartes açia tierra y dos medios y una plataforma sobre la mar encerrando todas las casas del arrabal de dicho lugar". Continuaba explicando que la fábrica contaría con "medias lunas, fosos, estrada encubierta, espaltos, terraplenes, cuerpos de guardia y almagacenes...", cuyo coste alcanzaría la extraordinaria cifra de 228.000 escudos ${ }^{23}$.

El diseño por Francisco de Isasi de una fortaleza en forma de estrella de ocho puntas y con cuatro bastiones (figura 7) se inspiraba en el proyecto de Ventura de Tarragona, que venía determinado por las instrucciones del rey: "porque Su Magestad manda que se pongan quatro valuartes solos en los quatro ángulos..."24. A diferencia del polígono de una sola línea planteado por Francisco de Lorenzana, el padre Isasi incluía obras exteriores, en este caso medias lunas. En este tipo de estructuras consistía la principal novedad que presentan los proyectos de fortificación desde inicios del siglo XVII. Como han señalado Cobos Guerra y Castro Fernández, la historiografía ha enfatizado las innovaciones que siguiendo dicha premisa se desarrollaron en Francia bajo la dirección del marqués de Vauban durante la segunda mitad del siglo XVII, sin advertir que los ingenieros españoles e italianos habían comenzado a planificar defensas exteriores en sus fortificaciones de Lombardía desde el decenio de 1620, auspiciadas desde 1618 por el duque de Feria (Cobos y Castro, 2005, p. 76). Esta experiencia, que incorporaba soluciones ya adoptadas por los españoles en Flandes, se vería reflejada en numerosos informes y planos, como el de la fortaleza de Bornio en la Valtelina, que data de 1620 (fig. 8).

El diseño de esta fortaleza alpina es prácticamente idéntico al delineado el 28 de enero de 1649 por Francisco de Isasi en Vinaròs, lo que demuestra que la incorporación de obras exteriores a las fortalezas en el contexto de la guerra de Cataluña gozaba de una larga tradición entre los ingenieros de la monarquía hispánica que ahora se afanaban en aplicar. Este legado de la Escuela hispanomilanesa de ingenieros habría servido a los intereses de la monarquía hispánica en la península ibérica una vez aquellos ingenieros fueron desplazados de Milán a España ante la creciente amenaza francesa de la década de 1630. Francisco de Isasi, que procedía de Madrid, había sido destinado a los fuertes de Ziburu y Guetaria desde enero de 1636 a mayo de 1638, y desde ese momento

23 AGS, GA, leg. 1706, el barón de Seebach al conde de Oropesa, 30/11/1648.

${ }^{24}$ AGS, GA, leg. 1742, Isasi al virrey, 28/1/1648. 
Fig. 7. Plano del proyecto de Isasi para Vinaròs, 1649. España. Ministerio de Educación Cultura y Deporte, Archivo General de Simancas, MPD, 64-49, 43 x $31 \mathrm{~cm}$.

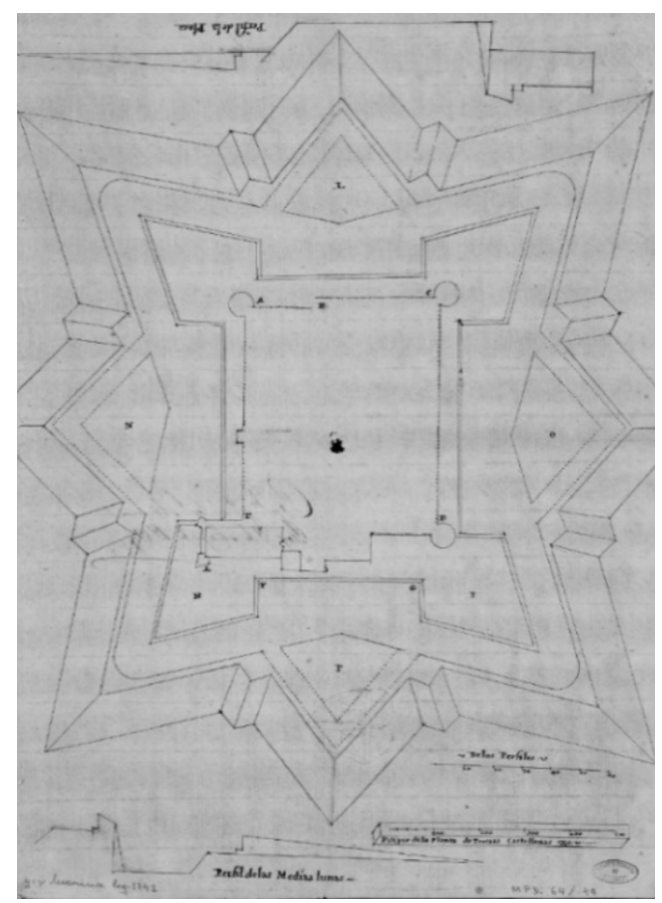

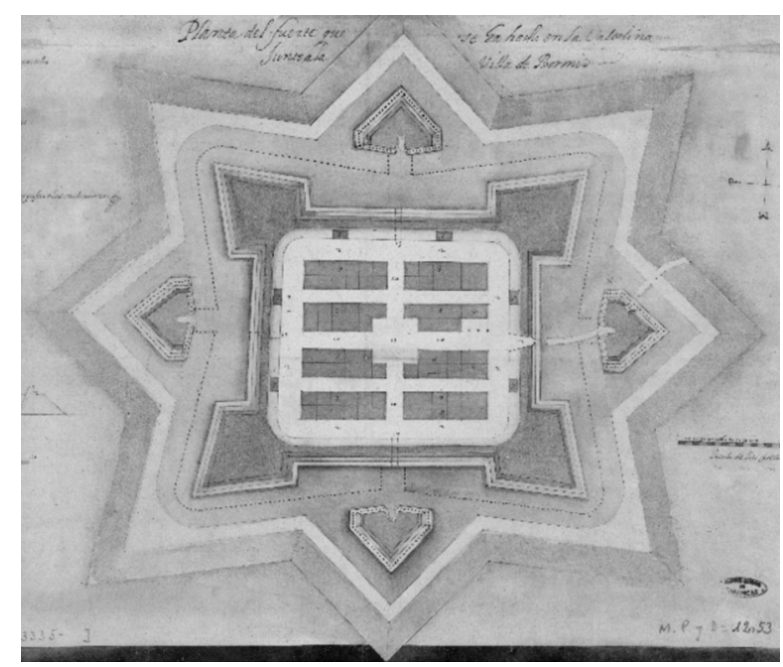

Fig. 8. Plano del fuerte de Bornio (Valtelina) de Juan Ayzaga, 1620. España. Ministerio de Educación Cultura y Deporte, Archivo General de Simancas, MPD, 36-13, 49 x $35 \mathrm{~cm}$. 
a Fuenterrabía, como él mismo nos cuenta ${ }^{25}$, y como profesor en el Colegio Imperial conocía muy bien las innovaciones adoptadas en Milán. Este movimiento de ingenieros hacia fortalezas de toda la península ibérica, y, por tanto, el intercambio de ideas, se aceleró tras la sublevación de Cataluña y Portugal en 1640 (Cobos y Castro, 2005, p. 80).

Para la construcción de la fortaleza de Vinaròs el ingeniero vasco expuso que las 400 casas de los arrabales debían derribarse y aprovechar las piedras para formar el frente, una solución expeditiva común entre los ingenieros. Las cortinas se formarían mediante mampostería y los baluartes debían estar terraplenados y reforzados con estribos y contrafuertes. La parte más exterior se vestiría con piedra ${ }^{26}$. Esta idea quedaba reflejada perfectamente en el plano, que carece de las viviendas extramuros que sí representó Lorenzana. El diseño de cuatro bastiones de ángulos canónicos típicamente académicos partía de la idea de proyectar los ángulos de los baluartes en espuntón (agudos) tomando como referencia las torres y la iglesia, puntos fuertes que quedarían así protegidos por los traveses: "se pueden por aora fabricar los dos valuartes $\mathrm{A}$ y $\mathrm{C}$ en los puestos que se notan o desunidos de la plaça dándoles comunicación de los torreones o cubos con pontones...". Además de la prioridad por levantar los baluartes de levante, este testimonio demuestra que Vinaròs contaba con grandes torres en sus esquinas. Al ser descritas por Isasi como cubos redondos, la sospecha de que el virrey Oropesa había desconsiderado su auténtica naturaleza al describirlos como "torreoncillos" queda confirmada.

Las cuatro medias lunas que se incluían en el proyecto eran inexcusables según Isasi para "abrigar" de la mejor manera posible los anacrónicos lienzos antiguos: "si bien quedarán, aunque más cubiertas, de poco probecho por no poderse formar ni parapetos ni darse comunicación qual conviene para los baluartes". Dos de estas defensas exteriores (L y P) debían a su vez cubrir las dos puertas de entrada, situadas en la parte este y oeste, respetando así las dos entradas principales a la villa. Isasi consideró inaplazable alzar también la cortina que unía los puntos $\mathrm{F}$ y $\mathrm{G}$ para proteger la iglesia, ya que la torre era insuficiente y la caponera incorporada en el lado norte carecía a su vez de otras defensas. Isasi insistía en que cada uno de los puntos de la fortaleza debía estar apoyado y reforzado mediante una defensa interior o exterior, en un sistema geométrico perfectamente simétrico e interdependiente. Según el matemático en dos meses podría concluirse la obra de los cuatro baluartes con la cortina si se empleaban 60 canteros, 120 peones y 220 gastadores.

25 AGS, GM, leg. 1706, Isasi al Consejo de Guerra, septiembre 1648.

26 AGS, GA, leg. 1742, Isasi al rey, 28/1/1648. 


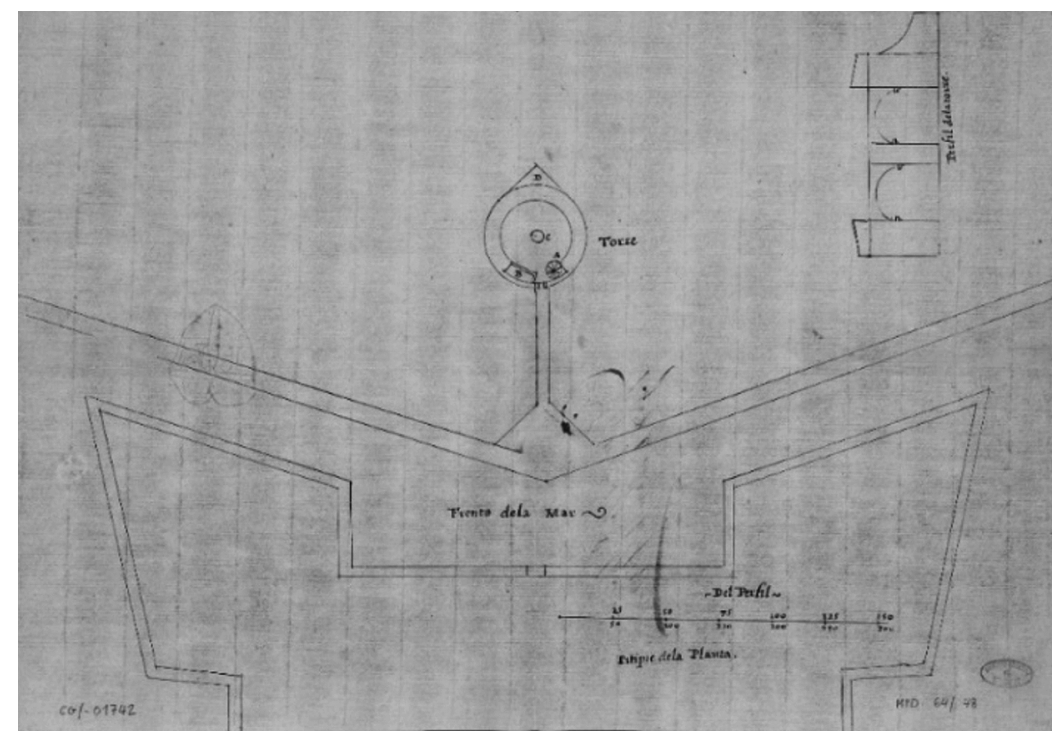

Fig. 9. Plano de una torre fortificada para la fortaleza de Vinaròs de Francisco de Isasi, 1649. España. Ministerio de Educación Cultura y Deporte, Archivo General de Simancas, MPD, 64-48, 31 x $43 \mathrm{~cm}$.

El proyecto recogía también la idea del ingeniero Tarragona relativo a la construcción de una torre cilíndrica en el mar que pudiera albergar artillería en la parte superior, de la que diseñó otro plano, y que debía ubicarse en el mismo lugar donde "el maestre de campo Tarragona ponía su plataforma..." 27 (fig. 9). Como era preceptivo, el ingeniero siguió también los principios modernos en una obra de estas características. La torre debía poder defenderse desde todos sus ángulos, de manera que Isasi pensó en una solución: por la parte del mar "se le añade su punta para que todo se flanquee de los trabeses..." y por tierra debía construirse una plataforma abovedada para comunicarse con la fortaleza.

Mientras el fuerte de Vinaròs era solo un proyecto, en Traiguera continuaban las obras ${ }^{28}$ de una fortaleza que finalmente pudo construirse en dos años y

27 AGS, GA, leg. 1742, don Francisco de Isasi al rey, 28/1/1648.

28 AGS, GA, leg. 1742, Copia del parezer del maestre de campo varón de Sebach sobre la conveniencia de fortificar a Traiguera, 23/I/1649. Id. el conde de Oropesa al rey, 21/1/1649. 
cuyos últimos trabajos se abandonaron tras la recuperación de Tortosa en diciembre de 1650. Isasi las había inspeccionado al llegar a la frontera y propuso reorientar ligeramente cinco baluartes del hexágono, cuya traza seguía el proyecto inicial de Pedro Alexandre. Para presentar su informe diseñó un sencillo plano con las nuevas líneas de los bastiones ${ }^{29}$. A su cargo quedaron las obras durante meses hasta que muriese a pie de obra como consecuencia de un desprendimiento de tierra de la muralla en mayo de $1650^{30}$.

La temida ofensiva francesa no se desató en la primavera y verano de 1649, aunque no tardaría en desatarse. El 1 de noviembre, en el contexto del inusitado avance sobre Barcelona que había protagonizado el ejército real de Juan de Garay, quien no logró alcanzar su objetivo último, comenzó la invasión. En la operación de diversión planeada por el general Ferdinand Marchin en el Maestrazgo, con la intención de obligar a los españoles a dividir sus fuerzas, participaron 1.800 infantes y 800 caballeros bajo el mando de don Josep d'Ardena, general de caballería catalán, conde d'Ille y mariscal de Francia. Durante el transcurso de tres semanas las tropas saquearon sucesivamente Sant Jordi, Càlig, La Jana, Canet lo Roig, Xert y Salzadella, para luego poner sitio por dos veces a Sant Mateu, aunque no consiguieron doblegar a los defensores. Estos acontecimientos fueron registrados en una detallada Información encargada por el virrey. Desde el punto de vista francés contamos con las noticias de este episodio publicadas en la Gazette bajo el título Iournal de la Marche \& entrée de l'armée du Roy dans le Royaume de Balance sous le commandement du Comte d'Ille (janvier, 1650) (Hernández, 2013, pp. 6-46). La resistencia presentada por el barón de Seebach, los refuerzos que llegaron desde Castellón y las noticias del desembarco en Peníscola de infantería procedente de Tarragona arruinaron el plan de Ardena, que abandonó la idea de tomar Sant Mateu el 22 de noviembre. El pánico que causaron estos hechos explica la continuación de los trabajos en Traiguera, para los que los Estamentos solicitaron una contribución general a todo el reino y se destinaron recursos de la Taula de Canvis (Felipo, 2010, pp. 321-324). Cuando se produjo la recuperación definitiva de Tortosa por las fuerzas del marqués de Mortara en diciembre de 1650 se volvió a la situación anterior a la del verano de 1648. La frontera valenciana dejaba atrás la primera línea de frente y la fortificación de Traiguera dejó de considerarse imprescindible. Las obras se detuvieron y con ellas los proyectos de la fortaleza de Vinaròs.

29 AGS, MPD, 64/50. Plano de Francisco de Isasi. Traiguera, 28/I/1649. AGS, GA, leg. 1742: "Los valuartes pudieran tener mejor forma excepto el que cae sobre la fuente que no permite otra disposición...”. AGS, GA, leg. 1742. Francisco de Isasi al virrey, 28/1/1649.

30 AGS, GA, leg. 1775, el conde de Oropesa al rey, 24/5/1650. 


\section{CONCLUSIÓN}

La idea de fortificar la frontera valenciana en el contexto de la guerra de Cataluña (1640-53) surgió en el Consejo de Guerra tras el primer asedio de Tortosa en abril de 1642. Aunque el capitán valenciano Baltasar Fort fue enviado allí en febrero de 1643 para acometer el plan, la conservación de Tortosa suspendió el proyecto. Hasta ese momento, las poblaciones de la frontera valenciana mantenían el sistema defensivo que las había guarnecido durante las décadas precedentes, basado esencialmente en la movilización de la milicia y, a excepción de Vinaròs y Peñíscola en un sistema murario que databa de la edad media. Como en el resto del reino, la concepción estratégica se fundamentaba todavía en la defensa de la costa, donde el peligro de desembarco berberisco la seguirá amenazando durante decenios. Las únicas obras modernas que se habían emprendido hasta 1640 para reforzar la defensa de la franja costera septentrional del reino se acometieron en la muralla moderna de Peníscola (1578) y en Vinaròs (1560 y 1594).

Nada más producirse la caída de Tortosa en manos francesas el 12 de julio de 1648 una junta reunida en Sant Mateu recuperó el plan de fortificar la frontera y don Francisco de Melo ordenó al teniente de maestre de campo Pedro Alexandre, al mando de las obras de fortificación del ejército real, que proyectase su construcción en Traiguera y Vinaròs. Las obras comenzaron en Traiguera en agosto, bajo la supervisión del ingeniero don Francisco de Lorenzana y Castro, quien elaboró también sus propios proyectos para Traiguera y Vinaròs, como hicieron posteriormente los ingenieros don Ventura de Tarragona y Francisco de Isasi. Los planos conservados en el Archivo de Simancas nos muestran la magnitud de unas obras (Traiguera) y proyectos (Vinaròs) que conjugaban la belleza estética y la proporción matemática heredada del Renacimiento pero también la adaptación a las condiciones geográficas. La idea en Vinaròs consistía en levantar una fortaleza real pentagonal (Francisco de Lorenzana, 1648) o tetragonal de ángulos agudos (Francisco de Isasi, 1649), mediante bastiones canónicos protegidos en la obra de Isasi por medias lunas y un gigantesco glacis que circunvalaría la población. Esta segunda opción se completaba con la construcción de una torre cilíndrica en el mar. Ambos proyectos integraban el recinto murario anterior a 1648, que disponía de tres grandes torres redondas y una iglesia-fortaleza que facilitaba el uso de armas de fuego. Las obras exteriores planteadas para construir medias lunas, y en el caso de Isasi el proyecto en su conjunto, recogían concepciones modernas de la defensa planteadas por los ingenieros italianos y españoles de la escuela de Milán desde el decenio de 1610. Si finalmente el proyecto de Vinaròs no se llevó a cabo se debió a la concentración de todos los recursos en la fortaleza de Traiguera y la recuperación de Tortosa por los españoles en diciembre de 1650. 


\section{BIBLIOGRAFÍA}

ALBIOL VIDAL, S. (2003): Establiments de Vinaròs. Un estudi de dret foral valencià del segle XVII, Serie Història del Maestrat, 4, Benicarló, Centro de Estudios del Maestrazgo.

ARCINIEGA GARCÍA, L. (1999): "Defensas a la antigua y a la moderna en el Reino de Valencia durante el siglo XVI", Espacio, Tiempo y Forma, Serie VII, Historia del Arte, UNED, Madrid, t. 12, pp. 61-94.

ARCINIEGA GARCÍA, L. (2016) "El baluarte y la casa de Armas de Valencia en tiempos de Cervantes: proceso constructivo y seña de identidad foral”, Ars Longa. Cuadernos de Arte, 25, Valencia, Universitat de València, pp. 115-142.

BAILA PALLARÉS, M. A. (2008): Lloc, Vila i Ciutat: evolució urbana de Vinaròs (segles XIII-XX), Vinaròs, Antinea.

BELCHÍ NAVARRO, P. (2006): Felipe II y el virreinato valenciano (1567-1578). La apuesta por la eficiencia gubernativa, Valencia, Biblioteca Valenciana.

BORRÀS JARQUE, J. M. (1929), reedición de 2001: Història de Vinaròs, Tortosa, t. I, facsímil, Vinaròs, Ajuntament de Vinaròs.

BUNES IBARRA, M. A. (1998): “Felipe II y el Mediterráneo: la frontera olvidada y la frontera presente de la monarquía católica", en: MARTÍNEZ MILLÁN, J. (dir.), Felipe II (1527-1598). Europa y la monarquía católica, t. I, Madrid, Parteluz, pp. 97-110.

CÁMARA MUÑOZ, A. (1989): “La fortificación de la monarquía de Felipe II”, Espacio, tiempo y forma, serie VII, Historia del Arte, Madrid, UNED, 2, pp. 73-80.

CÁMARA MUÑOZ, A. (2005): "Esos desconocidos ingenieros", en: Los ingenieros militares de la monarquía hispánica en los siglos XVI y XVII, Madrid, Ministerio de Defensa, pp. 13-33.

CÁMARA MUÑOZ, A. (2015): “La fortificación: el imperio de la geometría”, en: RIBOT, L. (coord.): Historia Militar de España, Edad Moderna. Escenario europeo, t. III, v. II, Madrid, Ministerio de Defensa, pp. 341-371.

CAMARERO PASCUAL, C. (2015): La Guerra de recuperación de Cataluña, 1640 1652, Madrid, Actas.

COBOS GUERRA, F. CASTRO FERNÁNDEZ, J. J. (2000): “Inicio y desarrollo de la fortificación moderna en el reino de Valencia, 1544-1579”, en: SÁNCHEZ GIJÓN, A.: Luis Escrivá. Su Apología y la fortificación imperial, Valencia, Biblioteca Valenciana.

COBOS GUERRA, F. CASTRO FERNÁNDEZ, J. J. (2005): “Los ingenieros. Las experiencias y los escenarios de la arquitectura militar española en el siglo XVII" en: CÁMARA MUÑOZ, A. (coord.), Los ingenieros militares de la monarquía hispánica en los siglos XVI y XVII, Madrid, Ministerio de Defensa, pp. 71-97.

DOMÍNGUEZ ORTIZ, A. (1996): Carlos III y la España de la Ilustración, Madrid, Alianza.

ELLIOTT, J. H. (1990): El conde-duque de Olivares, Barcelona, Crítica. 
FELIPO ORTS, A. (2010): "Servicios y donativos de la ciudad de Valencia a la monarquía durante la revuelta catalana”, Studia histórica. Historia moderna, 32, Salamanca, Universidad de Salamanca, pp. 305-333.

GARCÍA MARTÍNEZ, S. (1980): Bandolers, corsaris i moriscos, Valencia, sèrie "La Unitat", 62, Valencia, Eliseu Climent.

GASCÓN PÉREZ, J. (2014): “Aragón, ¿Tierra de bandoleros? El difícil mantenimiento del orden en un reino del siglo XVI", Estudis. Revista de Historia Moderna, 40, Valencia, Universitat de València, pp. 191-212.

GUÍA MARÍN, Ll. (1984): Cortes del reinado de Felipe IV. Cortes valencianas de 1645, Departamento de Historia Moderna, Valencia, Universitat de València.

HERNANDO SÁNCHEZ, C. J. (2013): "Non sufficit orbis? Las estrategias de la Monarquía de España”, en: RIBOT, L. (coord.): Historia Militar de España, Edad Moderna. Escenario europeo, t. III, v. II, Madrid, Ministerio de Defensa, pp. 29-77.

HERNÁNDEZ RUANO, J. (2013): “Incursiones y operaciones navales franco-catalanas sobre la frontera valenciana durante la Guerra dels Segadors. La invasión de don Josep d'Ardena (noviembre de 1649)", Boletín del Centro de Estudio del Maestrazgo, 89, Benicarló, pp. 6-46.

HERNÁNDEZ RUANO, J. (2014): Peñíscola Inexpugnable. La fortaleza y el Mediterráneo desde Carlos V a Alfonso XIII, Vinaròs, Quatre Colors.

HERNÁNDEZ RUANO, J. (2014b): Poderosos pleitos. Conflictividad, litigantes y estrategias judiciales en el señorío de la Orden de Montesa (siglos XVI y XVII), Col-lecció "Estudis jurídics", n 20, Castelló de la Plana, Universitat Jaume I.

ITURAT GARCÍA, J. (1989): "Noticias sobre las defensas y ataques a Alcalá”, Benicarló, Boletín del Centro de Estudios del Maestrazgo, 27, pp. 64-85.

OLIVER FOIX, A. (2000): La imagen de Vinaròs en la Historia, Vinaròs, Associació cultural Amics de Vinaròs.

OLIVER FOIX, A. (2007): Las fortificaciones de Vinaròs (s. XIII-XVIII). Evidencias arqueológicas y documentales, Vinaròs, Associació cultural “Amics de Vinaròs".

PARDO MOLERO, J. F. (2000): "Proyectos y obras de fortificación en la Valencia de Carlos V", Estudis. Revista de Historia Moderna, Valencia, Universitat de València, 26, pp. 137-176.

PARDO MOLERO, J. F. (2001): La Defensa del Imperio. Carlos V, Valencia y el Mediterráneo, Madrid, Sociedad estatal para la conmemoración de los centenarios de Felipe II y Carlos V.

PARKER, G. (2002): La revolución militar: innovación militar y apogeo de Occidente, 1500-1800, Madrid, Alianza.

PARROTT, D. (2000): “The Utility of fortifications in Early Modern Europe: Italian Princes and their Citadels, 1540-1640”, War in History, vol. 7, 2, pp. 127-153.

QUEROL COLL, E; MUÑOZ I SEBASTIÀ, J. H. (2004): La Guerra dels Segadors a Tortosa (1650-1651), Cossetània, Valls.

REQUENA AMORAGA, F. (1997): La defensa de las costas valencianas en la época de los Austrias, Alicante, Instituto alicantino de cultura Juan-Gil Albert.

SÁNCHEZ GIJÓN, A. (ed.), (2000): Luis Escrivá. Su Apología y la fortificación imperial, Valencia, Biblioteca Valenciana. 
SANMARTÍN BESALDUCH, A. (1990): "Les fortificacions de la vila de Traiguera (1641-1650)", Boletín del Centro de Estudios del Maestrazgo, Benicarló, 29, pp. 1732.

THOMPSON, I. A. A. (1981): Guerra y Decadencia. Gobierno y administración en la España de los Austrias (1560-1620), Barcelona, Crítica.

VICIANA, M. de (1564): Crónica de la ínclita y coronada ciudad de Valencia, València, edición facsímil del Departamento de Historia Moderna, Valencia, Universitat de València, 1972.

VV.AA. (2014): "La restauració de l'arxiprestal, un temple-fortalesa", en: VV.AA. Pulchra Magistri: l'esplendor del Maestrat a Castelló; Culla, Catí, Benicarló, Vinaròs, 2013-2014: Campanya de restauració patrimonial, La Luz de las Imágenes, Generalitat Valenciana, pp. 121-135. 